\title{
Barriers and facilitators to the implementation of electronic collection of patient-reported measures in routine care of older adults: Protocol for a qualitative evidence synthesis
}

\author{
Gayanika M. Hettiarachchi Senarath ${ }^{1}$, Pari Delir Haghighi ${ }^{1}$, Denise O'Connor ${ }^{2,3}$, David Snowdon ${ }^{4,5}$, Nadine \\ Andrew ${ }^{4,5}$, Velandai Srikanth ${ }^{4,5}$
}

Department of Human-Centred Computing, Department of Faculty of Information Technology, Monash University ${ }^{1}$

Department of Epidemiology and Preventive Medicine, School of Public Health and Preventive Medicine, Monash University ${ }^{2}$

Monash-Cabrini Department of Musculoskeletal Health and Clinical Epidemiology, Cabrini Health ${ }^{3}$

Department of Medicine, Central Clinical School, Peninsula Clinical School, Monash University ${ }^{4}$

Professorial Academic Unit, Frankston Hospital, Peninsula Health, Melbourne, Victoria, Australia ${ }^{5}$

\section{February 2022}

\section{INTRODUCTION}

By 2050, it is expected that 1 in 6 people in the world will be above the age of 65 years (United Nations, 2020), and life expectancy is continuing to rise in this population mainly due to better healthcare and living conditions, and technology advances (Mannheim et al., 2019; Marengoni et al., 2011). Older adults with multi-morbidity and complex care needs are frequent users of healthcare, and are likely to experience multiple care transitions between different settings (Gray et al., 2020). Hence, health systems are recognising the healthcare needs of this patient population, and increasingly involving older adults in the decisions made about the care they receive (Bunn et al., 2018). The use of patient-reported measures is one method of involving patients in the care they receive, through the administration of standardised validated questionnaires to collect data from the patient on health outcome and experience measures. Patient-reported measures, in the form of Patient Reported Outcome Measures (PROMs) and Patient Reported Experience Measures (PREMs) enable patients to report on their perception on health status, impairment, disability, health-related quality of life and experiences of the care process (Kingsley \& Patel, 2017; Weldring \& Smith, 2013; Wolpert, 2014). They are an important indicator of value-based care that intend to achieve patient-centered outcomes (Colldén \& Hellström, 2018), and used for health service improvements, research and benchmarking (Meirte et al., 2020; Paslakis et al., 2019; Remillard et al., 2014).

The electronic collection of patient-reported measures to capture patient-reported outcomes and experiences are gaining importance and are being implemented in routine care services (Kyte et al., 2016). Patient-reported measures collected electronically may be completed in various environments including hospital, home or work environments, using devices such as desktops, laptops, tablets and smartphones (Malhotra et al., 2016). The questionnaires may also be administered through mobile- or web-based applications (Hong et al., 2021; Meirte et al., 2020). The benefits of electronic collection of patient-reported measures include providing an end-to-end solution and process for information reporting by patients, integration to patient records, and improved accessibility and improved utilisation by healthcare professionals and health services for care improvements (Chang et al., 2019; De Rosis et al., 2020; Hernar et al., 2019; Meirte et al., 2020). Despite the evidence for the benefits, electronic collection of patientreported measures from older adults is seen as challenging (Lindhardt \& Nielsen, 2017; McCleary et al., 2013). Older adults face cognitive and physical challenges related to difficulties in hearing, vision, perception and altered cognition (Lindhardt \& Nielsen, 2017; McCleary et al., 2013) influencing the way they engage with digital technology to report their health outcomes and experiences. Additionally, the older adults' perception of the benefits of electronically collected patient-reported measures to inform and influence their care, and the care of others can impact the extent to which electronic reporting of patientreported measures is adopted by older adults (Meirte et al., 2020).

Evidence suggests feasibility of electronically collecting patient-reported measures in routine care (Hernar et al., 2019), in addition to older adult preferences in use and acceptability of electronic reporting of patient-reported measures (Hernar et al., 2019; Oliveira et al., 2011; Remillard et al., 2014; 
Tassiopoulos et al., 2020). Prior research has indicated barriers and facilitators to the use of e-health (health interventions delivered electronically - e.g. mobile applications to manage pain and chronic diseases) by older adults (Parker et al., 2013; Wilson et al., 2021), including the use of online questionnaires among older adults not limited to collecting patient-reported measures (Remillard et al., 2014). These factors have alluded to internal (i.e. physical, sensory, intellectual ability and motivation), external, technological and data sharing aspects (Remillard et al., 2014; Wilson et al., 2021). However, how and why these factors act in a certain way in the relevant context is not well understood. This has led to a gap in evidence about how best to implement electronic collection of patient-reported measures in older adult care. The involvement of older adults in the different stages of digital change to enable electronic collection of patient-reported measures to inform their care, and whether actual user needs are met, is also poorly understood (Mannheim et al., 2019; Remillard et al., 2014).

It is worth acknowledging that there is no clear distinction about the stage of digital change focussed in studies (i.e. plan, development, implementation and use) (Morton et al., 2021; Ross et al., 2018). Differences also exist in the interpretation of terminology around what each stage means (Craig et al., 2008; May, 2013; May et al., 2016; Moore et al., 2017; O'Cathain et al., 2019; Rousseau et al., 2019). For the purpose of this review, 'planning' is referred to as the process of identifying the intervention idea (e.g. electronic platform to collect patient-reported measures electronically), analysing the need for the intervention (i.e. based on problem or opportunity), and understanding the context (i.e. target population, stakeholder engagement, internal and external context) in which the identified intervention will be implemented. 'Development' is referred to as the process of defining and designing the intervention (i.e. solution, features of solution, content, format, delivery, prototypes) which can be formally evaluated through feasibility analysis or pilot testing. 'Implementation' is referred to as the process in which actions are initiated to introduce the intervention in a formal organisational setting that is formally defined and is intended to lead to a changed outcome and for routine use. 'Use' is referred to as the sustainment of an intervention in the formal organisational setting to maintain the desired outcomes and benefits associated with the introduction of the intervention.

To date, there is no qualitative evidence synthesis relating to the planning, development, implementation and use of electronic collection of patient-reported measures in the routine care of older adults, accounting for multiple stakeholder viewpoints. The systematic review published in 2014 on the use of online questionnaires among the older adults, synthesises evidence primarily on the limitations of online questionnaires for use among older adults, and methodologic approaches to population targeting and sampling (Remillard et al., 2014). This review is not specific for the purposes of electronic collection of patient-reported measures in the routine care of older adults, and also lacks the methodological rigour (i.e. no quality or confidence assessment) required in a qualitative evidence synthesis. Another systematic review published in 2020 synthesises evidence on the benefits and disadvantages to the use of online questionnaires for the collection of PROMs (Meirte et al., 2020). This review highlights the barriers and facilitators to electronically collecting PROMs, applicable in various patient populations (i.e. patients with specific medical conditions - cancer, skin condition, patients that underwent surgery, patients in rehabilitation programs and geriatric patients). Whilst this review does not solely focus on 'older adults' as a patient population, it provides useful indicators about what may promote and inhibit the adoption of electronic collection of patient-reported measures (i.e. access to digital technology, support needed to use digital technology) among older adults.

The reviews had primarily accounted for patient perspectives and experiences, but lack the perspectives and experiences of other closely associated stakeholders. Both these reviews lack clarity and specificity on the application of online questionnaires for the capture of health outcomes and experiences from older adults. How and why different barriers and enablers impact the way the intervention works, and how this is perceived by stakeholders including older adults, caregivers of older adults, healthcare professionals, administrators, researchers, information technology professionals and policy makers related to the functioning of the intervention, is also lacking. Hence, there is a need to understand how and why perceived barriers and facilitators from multiple stakeholder viewpoints may influence the planning, 
development, implementation and use of electronic collection of patient-reported measures in the routine care of older adults. In addition, no prior systematic reviews had also reported on the use of theory to understand factors relating to the planning, development, implementation and use of electronic collection of patient-reported measures in the routine care of older adults. Hence, a qualitative evidence synthesis will be conducted considering the multiple stakeholder views, considering the different stages involved in the digital life cycle of change and using a theoretical foundation to guide this evidence synthesis.

\section{Use of theoretical foundation for conceptualising the intervention}

The planning, development, implementation and use of electronic collection of patient-reported measures in the routine care of older adults requires behaviour change at an individual and population level in multiple agents (i.e. patient, caregiver of patient, clinician) (May, 2013; Michie et al., 2011). This digital intervention intended to be used by older patients to report their health outcomes and experiences (regarded as a complex intervention) in healthcare systems (regarded as complex adaptive systems) is associated with complexity due to heterogeneity of the agents involved, how they interact with each other and outcomes resulting from these interactions that tend to lead to iterative adaptations (Braithwaite et al., 2018; Plsek \& Greenhalgh, 2001). Hence, the use of theoretical foundation based on behaviour change and complexity science taking a view outside of linear thinking will be beneficial to guide the appraisal of the factors influencing the planning, development, implementation and use of electronic collection of patient-reported measures in the routine care of older adults, and lead towards identification of effective approaches to plan, develop, implement and use electronic collection of patient-reported measures.

For the purpose of this review, the Capability, Opportunity, Motivation and Behaviour (COM-B) model underpinned by behaviour change theory (Michie et al., 2011), and the Non-adoption, Abandonment, and challenges to the Scale-up, Spread, and Sustainability (NASSS) framework underpinned by complexity science (Greenhalgh et al., 2017) will be used to map data to the theoretical constructs, and guide the data analysis. In intervention development, the COM-B model is considered as a starting point which aids in the understanding of how capability, opportunity and motivation components interact to produce a certain behaviour towards the electronic reporting of patient-reported measures in the routine care of older adults. The COM-B components can be further elaborated into the 14 domains of the Theoretical Domains Framework (TDF) to increase the explanatory power of the evidence synthesis (McDonagh et al., 2018; Michie et al., 2014; Timlin et al., 2021). The NASSS framework relates to 7 domains: understanding the patient's medical condition, digital technology, value proposition for key stakeholders, adopter system, organisational factors, external factors, and adaptations over time (Greenhalgh et al., 2017). The use of this framework will enable manifestation of factors contributing to complexities across these seven domains in planning, development, implementation and use of electronic collection of patient-reported measures in the routine care of older adults. The use of COM-B model to understand individual and population level behaviour change factors can complement further understanding of the behaviour change factors that relate to certain domains in the NASSS framework (i.e. patient condition, adopter system, value proposition) involved with planning, development, implementation and use of electronic collection of patient-reported measures in the routine care of older adults. The use of these two frameworks will enable data extraction, analysis and synthesis through a theory-informed approach, while increasing the theoretical generalisability and transferability, and providing grounds for synthesis comparability. In addition, this gives an opportunity to test the COM-B and NASSS framework application independently and in combination, within the context of electronic collection of patient-reported measures in the routine care of older adults.

\section{Aim}

To synthesise qualitative research evidence on barriers and enablers influencing the planning, development, implementation and use of electronic collection of patient-reported measures in the routine care of older adults, considering multiple viewpoints including but not limited to older adults aged 65 
years and above, caregivers of older adults, administrators, healthcare professionals, researchers, information technology professionals and policy makers, and to organise the findings using the COM-B and NASSS frameworks.

\section{Review Question}

The primary review question is: 'What are the barriers and facilitators to the planning, development, implementation and use of electronic collection of patient-reported measures in routine care of older adults?'

The review question has been developed through the use of the PerSPecTIF question framework considered particularly suitable for complex intervention reviews within qualitative evidence synthesis (Booth et al., 2019).

\begin{tabular}{|c|c|c|c|c|c|c|}
\hline Per & $S$ & $\mathbf{P}$ & $\mathbf{E}$ & (C) & $\mathbf{T i}$ & $\mathbf{F}$ \\
\hline Perspective & Setting & $\begin{array}{c}\text { Phenomenon of } \\
\text { Interest/ } \\
\text { Problem } \\
\end{array}$ & Environment & $\begin{array}{c}\text { Comparison } \\
\text { (optional) }\end{array}$ & Time/Timing & Findings \\
\hline $\begin{array}{l}\text { From } \\
\text { perspective of: } \\
\text { Older adults } \\
\text { aged } 65 \text { years } \\
\text { and above } \\
\text { Caregivers of } \\
\text { older adults } \\
\text { Healthcare } \\
\text { professionals } \\
\text { Administrators } \\
\text { Researchers } \\
\text { Information } \\
\text { Technology } \\
\text { Professionals } \\
\text { Policy Makers }\end{array}$ & $\begin{array}{l}\text { In setting of: } \\
\text { Healthcare } \\
\text { including } \\
\text { hospital, } \\
\text { primary } \\
\text { care, long } \\
\text { term care, } \\
\text { community } \\
\text { care and } \\
\text { residential } \\
\text { aged care }\end{array}$ & $\begin{array}{l}\text { How does the } \\
\text { phenomenon of } \\
\text { electronic } \\
\text { collection of } \\
\text { patient-reported } \\
\text { measures in older } \\
\text { adult care }\end{array}$ & $\begin{array}{l}\text { Within } \\
\text { environments, } \\
\text { not limited to } \\
\text { hospital, } \\
\text { primary, long } \\
\text { term, } \\
\text { community } \\
\text { care, home and } \\
\text { work } \\
\text { environments }\end{array}$ & - & $\begin{array}{l}\text { During planning } \\
\text { During } \\
\text { development } \\
\text { (i.e. electronic } \\
\text { collection } \\
\text { system } \\
\text { development, } \\
\text { data integration, } \\
\text { consumer/clinic } \\
\text { ian interface } \\
\text { development) } \\
\text { During } \\
\text { implementation } \\
\text { During use: on } \\
\text { admission, } \\
\text { discharge, post } \\
\text { discharge }\end{array}$ & $\begin{array}{l}\text { Relate to } \\
\text { perceptions } \\
\text { (barriers and } \\
\text { enablers) of: } \\
\text { Older adults } \\
\text { aged } 65 \text { years } \\
\text { and above } \\
\text { Caregivers of } \\
\text { older adults } \\
\text { Healthcare } \\
\text { professionals } \\
\text { Administrators } \\
\text { Researchers } \\
\text { Information } \\
\text { Technology } \\
\text { Professionals } \\
\text { Policy Makers }\end{array}$ \\
\hline
\end{tabular}

\section{METHODS}

\section{Criteria for considering studies for this review:}

\section{Type of studies}

Primary studies that use qualitative study designs, that use qualitative methods to collect data (i.e. interviews, focus groups, ethnography) and qualitative methods to analyse data (i.e. thematic analysis, framework analysis, grounded theory) will be included. Studies with mixed-method designs with qualitative data collection and analysis, and where these qualitative components and findings can be determined will be included. Studies published in English language only will be considered. Studies with quantitative study designs, descriptive studies, and other sources such as opinion papers, books, guidelines, policies, editorials and dissertations will be excluded. Unpublished studies will also be excluded.

\section{Type of participants (perspectives)}

Participants that may have had a part to play in the planning, development, implementation or use of electronic collection of patient-reported measures in the routine care of older adults have been 
considered. Their views are likely to provide insights on factors influencing the planning, development, implementation or use of electronic collection of patient-reported measures in older adult care:

- Older adults aged 65 years and above, and caregivers of older adults being the primary users of digital technology (e.g. smart phones administering mobile-based questionnaire) to report their health outcomes and experiences, may have been involved in the planning, development, implementation or use of electronic collection of patient-reported measures in their routine care They may also be accessing their own data through digital technology to be involved in their care decisions.

- Healthcare professionals and researchers are key users of the patient-reported measures collected electronically to improve care or research output, and their work practices. They may also be involved in the administration process of electronically collecting patient-reported measures from the older adults or their caregivers. Hence, they are likely to be influenced by the use of electronic collection of patient-reported measures, and may have been involved in the planning, development, implementation or use of electronic collection of patient-reported measures in the routine care of older adults.

- Other stakeholders including administrators, information technology professionals and policy makers, may be involved in the electronic collection of patient-reported measures. For instance, administrators may be involved in the administration process of collecting patient-reported measures electronically, information technology professionals may be involved in all digital technology related aspects not limited to data integration and interface development, and, policymakers maybe involved in driving policy around the use of electronic collection of patientreported measures. Hence, they may have been involved in the planning, development, implementation or use of electronic collection of patient-reported measures in older adult care. This may provide useful insights on the various factors influencing these stages.

- Studies reporting on patient or caregiver views, that recruited patient participants aged 65 years and above, or caregiver participants of older adults (aged 65 years and above) will be included. Studies reporting on other stakeholder views (i.e. healthcare professionals, administrators, information technology professionals, policy makers, researchers) that do not report the age group of patients considered (i.e. 65 years and above), but present evidence in relation to older adults (e.g. refer to factors relating to older adults) in results and discussion sections will be considered. In order to meet this threshold criteria, studies recruiting participants 18 years and above will be included.

\section{Type of settings and environments}

Studies describing planning, development, implementation or use of electronic collection of patientreported measures in routine care of older adults in healthcare settings including hospital, primary care, long term care, community care and residential aged care, irrespective of the clinical specialty (e.g. general, cardiac disease, digestive disease) will be included. Clinical trial research settings will be excluded. Given electronic collection of patient-reported measures can be completed at multiple time intervals (e.g. at the time of admission, during hospital stay, at the time of discharge and post discharge), studies describing electronic collection of patient-reported measures in older adult care in environments, not limited to hospital, home or work environments will be included.

\section{Type of findings}

Studies that report perceptions about barriers and facilitators in relation to planning, development, implementation or use of electronic collection of patient-reported measures in the routine care of older adults will be included. Evaluation of planning, development, implementation or the use of electronic collection of patient-reported measures will be considered.

Studies exploring the following topics will not be a focus of this review and will be excluded: 
- Internet-based interventions (e.g. telehealth, patient portals) for care management

- Electronic questionnaire use by age groups other than older age groups (e.g. paediatric population), for reporting patient-reported measures or other experiences (e.g. internet use or other)

- Electronic questionnaires intended to capture clinician-reported outcomes

Study Inclusion/Exclusion Criteria:

\begin{tabular}{|c|c|c|c|c|}
\hline & $\begin{array}{c}\text { Phenomenon of } \\
\text { Interest }\end{array}$ & $\begin{array}{c}\text { Target population } \\
\text { receiving intervention }\end{array}$ & $\begin{array}{c}\text { Setting and } \\
\text { Environment }\end{array}$ & Type of Studies \\
\hline $\begin{array}{c}\text { Inclusion } \\
\text { criteria }\end{array}$ & $\begin{array}{l}\text { Intervention must } \\
\text { include electronic } \\
\text { collection of } \\
\text { patient-reported } \\
\text { measures in the } \\
\text { routine care of } \\
\text { older adults } \\
\text { Perspectives, views } \\
\text { and experiences of } \\
\text { patients and/or } \\
\text { other related } \\
\text { stakeholders } \\
\text { (Caregivers of } \\
\text { Patients, } \\
\text { Healthcare } \\
\text { professionals, } \\
\text { Administrators, } \\
\text { Researchers, } \\
\text { Information } \\
\text { Technology } \\
\text { Professionals, } \\
\text { Policy Makers) } \\
\text { about barriers and } \\
\text { enablers must be } \\
\text { included } \\
\text { Stage of evaluation } \\
\text { to include } \\
\text { planning, } \\
\text { development, } \\
\text { implementation or } \\
\text { use }\end{array}$ & $\begin{array}{l}\text { Older adults aged } 65 \\
\text { years and above } \\
\text { - When considering } \\
\text { patient views, } \\
\text { recruited sample } \\
\text { should report } \\
\text { participants aged } 65 \\
\text { years and above } \\
\text { When considering } \\
\text { other stakeholder } \\
\text { views, study should } \\
\text { report factors relating } \\
\text { to older adults (even if } \\
\text { age is not specified) in } \\
\text { the results and } \\
\text { discussion sections } \\
\text { Studies recruiting } \\
\text { adults aged } 18 \text { years } \\
\text { and above will be } \\
\text { considered }\end{array}$ & $\begin{array}{l}\text { - In healthcare } \\
\text { setting(s) including } \\
\text { hospital, primary care, } \\
\text { long term care, } \\
\text { community care and } \\
\text { residential aged care, } \\
\text { in any clinical } \\
\text { specialty } \\
\text { - Environment of } \\
\text { electronic collection } \\
\text { of patient-reported } \\
\text { measures to include } \\
\text { all environments not } \\
\text { limited to hospital, } \\
\text { home or work }\end{array}$ & $\begin{array}{l}\text { - Primary studies } \\
\text { that include } \\
\text { qualitative or } \\
\text { mixed method } \\
\text { study designs, that } \\
\text { report use of } \\
\text { qualitative } \\
\text { methods for both } \\
\text { data collection } \\
\text { and data analysis }\end{array}$ \\
\hline
\end{tabular}




\begin{tabular}{|c|c|c|c|c|}
\hline $\begin{array}{c}\text { Exclusion } \\
\text { criteria }\end{array}$ & $\begin{array}{l}\text { Electronic } \\
\text { questionnaires } \\
\text { intended to } \\
\text { capture clinician- } \\
\text { reported outcomes } \\
\text { and experiences, or } \\
\text { other measures not } \\
\text { related to patient- } \\
\text { reported measures } \\
\text { from age groups } \\
\text { below } 65 \text { years } \\
\text { - } \\
\text { Studies that focus } \\
\text { on intervention } \\
\text { effectiveness only }\end{array}$ & 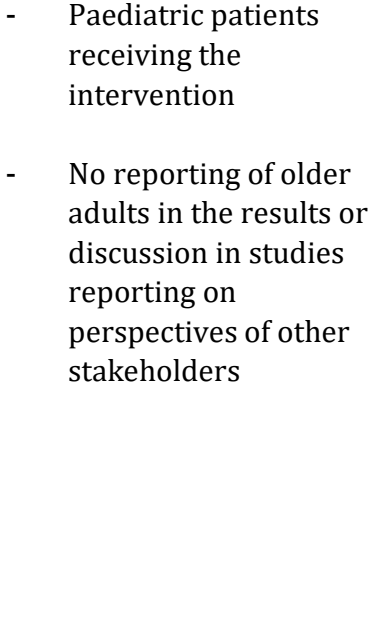 & $\begin{array}{l}\text { - In clinical trial } \\
\text { research setting }\end{array}$ & $\begin{array}{l}\text { - } \text { Primary studies } \\
\text { with quantitative } \\
\text { study designs } \\
\text { - Systematic } \\
\text { reviews } \\
\text { - Descriptive } \\
\text { studies } \\
\text { - Opinion papers, } \\
\text { commentaries, } \\
\text { editorials, } \\
\text { dissertations } \\
\text { - Unpublished } \\
\text { studies } \\
\text { - Policies } \\
\text { - Guidelines } \\
\text { - Study protocols }\end{array}$ \\
\hline
\end{tabular}

\section{Search Methods}

A search strategy will be developed with the assistance from an Information Specialist based at Monash University, guided by the Cochrane Qualitative Research Method Group's guidelines (Noyes et al., 2021). The following electronic databases will be searched from January 2001 - October 2021: MEDLINE (via OVID), CINAHL Plus (EBSCO host) and Web of Science. With a surge of relevant articles only being reported after 2006, seemingly due to the wider adoption of electronic collection of patient-reported measures, the mentioned year range is considered. The search will be limited to studies published in English only. The reference list of the studies included in the review will also be searched to find further relevant studies (Horsley et al., 2011; Wohlin et al., 2020).

\section{Deriving the search strategy:}

A preliminary search was conducted to identify key articles which are established as the 'gold set' related to the topic of review. This gold set was used to identify and test the search strategy in the databases. In addition, systematic reviews and relevant literature was reviewed to derive key words manually to ensure the search strategy was inclusive to meet relevance. Three main concepts based on the review question were categorised as 'patient-reported measures', 'electronic surveys or questionnaires' and 'qualitative research terms'. The key words were mapped to the relevant concept, and applicable references used in deriving the key words were documented.

\section{Selection of Studies}

Two review authors will independently screen all titles and abstracts yielded from the search, and all fulltext articles using the PerSPecTIF framework to evaluate eligibility. Any disagreements will be resolved via discussion, and by consultation with a third review author when necessary. Search and screening results will be summarised in a Preferred Reporting Items of Systematic Reviews and Meta-Analyses (PRISMA) flow diagram (Moher et al., 2009).

\section{Data Collection}

Two review authors will independently extract data from each included study using a pre-determined data collection form. Any disagreements will be resolved via discussion between the review authors, and if necessary with the review team. A data extraction form will be piloted on two included studies prior to capturing the following information:

- Study details (Authors, year of publication)

- Research question

- Method of data collection (e.g. interview, focus group)

- Data analysis method (e.g. thematic) 
- Participants (number, demographic attributes)

- Technological design features - (type of electronic questionnaire - e.g. web-based, mobile-based and mode of administration - e.g. laptop, smart phone, clinic kiosk)

- Intervention delivery features (e.g. education)

- Setting (e.g. clinical service line, country, questionnaire administration setting)

- Stage of evaluation (e.g. planning, development, implementation or use)

- Results (e.g. themes, sub-themes, supporting quotes)

\section{Quality Assessment}

Two review authors will independently assess the quality (methodological limitations) of included studies using the Critical Appraisal Skills Programme (CASP) Checklist (CASP, 2020). All eligible studies will be included irrespective of quality. Any disagreements will be resolved via discussion or by consultation with a third review author when necessary. A table summarising the quality assessment by addressing the CASP checklist items against each study will be included, and a narrative summary of the quality of the included studies will be provided.

\section{Data extraction, analysis and synthesis}

An inductive coding approach will be used to conduct a thematic synthesis (Thomas \& Harden, 2008). Coding of text 'line-by-line' will be done on each line (first step) of extracted text to develop descriptive themes (second step). Themes will be reviewed and revised with new codes as each new study review progresses. Coded text will be reviewed for mapping against the codes and coding consistency across all studies. All studies will be independently coded by two review authors and any discrepancies discussed with the review team until agreed. The COM-B and NASSS frameworks will then be used for mapping of emerging themes to the constructs of these frameworks independently by the two review authors. Emerging themes will be placed in 'other' category when there is no construct within COM-B and/or NASSS frameworks to map against. The primary review author will prepare a summary of descriptive themes aligned with the constructs within the COM-B and NASSS frameworks, in relation to the barriers and enablers to planning, development, implementation and use of electronic patient-reported measures in the routine care of older adults, considering perspectives from multiple stakeholders including but not limited to older adults aged 65 years and above (patients), patient caregivers, healthcare professionals, information technology professionals, researchers, administrators and policy makers. The review findings will be discussed with the review team to reach consensus.

\section{Assessment of confidence in review findings}

Two review authors will independently assess the confidence in the descriptive review findings using the Grading of Recommendations Assessment, Development, and Evaluation (GRADE) Confidence in the Evidence from Reviews of Qualitative (CERQual) research tool. The following four components will be considered to assess the confidence in the review finding (Lewin et al., 2018).

- Methodological limitations of included studies - the extent to which there are concerns about the design or conduct of the primary studies that contributed evidence to an individual review finding. CASP assessment will inform this component.

- Coherence of the review finding - an assessment of how clear and cogent the fit is between the data from the primary studies and a review finding that synthesises that data. By 'cogent', we mean well supported or compelling

- Adequacy of data - an overall determination of the degree of richness and quantity of data supporting a review finding

- Relevance - the extent to which the body of evidence from the primary studies supporting a review finding is applicable to the context (perspective or population, phenomenon of interest, setting) specified in the review question. PerSPecTIF framework used to determine study eligibility will inform this component. 
The overall confidence in the review finding will be judged as high, moderate low or very low. The final assessment of confidence will be discussed among the review team to reach consensus. A summary of the qualitative findings table will be presented on details of the confidence assessment.

\section{Reporting}

The search and screening results will be reported according to the Preferred Reporting Items for Systematic Reviews and Meta-Analysis (PRISMA) flowchart (Moher et al., 2009) and the study reported according to the Enhancing transparency in reporting the synthesis of qualitative research statement (ENTREQ) (Tong et al., 2012)

\section{Ethics and dissemination}

Ethical approval is not required to conduct this review. Results will be published in a peer-reviewed journal. This review protocol is also registered on the International Prospective Register of Systematic Reviews (PROSPERO; https://www.crd.york.ac.uk/prospero/), number CRD42022295894.

\section{Discussion}

This is a design of a qualitative evidence synthesis using the COM-B model and NASSS framework, to explore barriers and facilitators to the planning, development, implementation and use of electronic collection of patient-reported measures in the routine care of older adults. Stakeholder perspectives from older adults aged 65 years and above, caregivers of older adults, healthcare professionals, administrators, information technology professionals, researchers and any others will be explored. Key findings will inform the development of a logic model of change that will guide the development of a tailored intervention for electronic collection of patient-reported measures in the routine care of older adults, within the community rehabilitation service in a public health service.

\section{Strengths of this Study:}

- This study will inform development of a theory-informed logic model of change to guide planning and design of an electronic questionnaire for use by older adults to report their health status and experiences

- The use of COM-B and NASSS frameworks will bring in structure to synthesise evidence and will enhance the explanatory power from a behaviour change and complexity science stance

- A novel question formulation framework PerSPEcTiF will be tested to determine its suitability to explore complex interventions

- To report confidence of review findings, Grading of Recommendations Assessment, Development, and Evaluation Confidence in the Evidence from Reviews of Qualitative Research (GRADECERQUAL) will be used

\section{Limitations of this Study:}

- Studies included will be limited to those published in English, relevant studies published in nonEnglish-language journals may be missed

\section{Contributions:}

- This qualitative evidence synthesis will contribute to the understanding of factors influencing the planning, development, implementation and use of electronic collection of patient-reported measures in older adult care, which can inform better planning, design and development; implementation and use of the intervention

- The use of NASSS framework, and the combination of NASSS and COM-B in a qualitative evidence synthesis is novel, and will provide grounds to test the applicability of the frameworks

- Qualitative evidence synthesis using the PerSPEcTiF question formulation framework to evaluate complex interventions is limited, hence will add to the knowledge of this framework applicability and usefulness 


\section{References:}

Booth, A., Noyes, J., Flemming, K., Moore, G., Tunçalp, Ö., \& Shakibazadeh, E. (2019). Formulating questions to explore complex interventions within qualitative evidence synthesis. BMJ Global Health, 4(Suppl 1), e001107. https://doi.org/10.1136/bmjgh-2018-001107

Braithwaite, J., Churruca, K., Long, J. C., Ellis, L. A., \& Herkes, J. (2018). When complexity science meets implementation science: A theoretical and empirical analysis of systems change. BMC Medicine, 16(1), 63. https://doi.org/10.1186/s12916-018-1057-z

Bunn, F., Goodman, C., Russell, B., Wilson, P., Manthorpe, J., Rait, G., Hodkinson, I., \& Durand, M.-A. (2018). Supporting shared decision making for older people with multiple health and social care needs: A realist synthesis. $B M C$ Geriatrics, 18(1), 165. https://doi.org/10.1186/s12877-018-0853-9

Chang, E. M., Gillespie, E. F., \& Shaverdian, N. (2019). Truthfulness in patient-reported outcomes: Factors affecting patients' responses and impact on data quality. Patient Related Outcome Measures, 10, 171-186. https://doi.org/10.2147/PROM.S178344

Colldén, C., \& Hellström, A. (2018). Value-based healthcare translated: A complementary view of implementation. BMC Health Services Research, 18(1), 681. https://doi.org/10.1186/s12913-018-3488-9

Craig, P., Dieppe, P., Macintyre, S., Michie, S., Nazareth, I., \& Petticrew, M. (2008). Developing and evaluating complex interventions: The new Medical Research Council guidance. BMJ, 337. https://doi.org/10.1136/bmj.a1655

Critical Appraisal Skills Programme (CASP). (2020, November 30). CASP Checklist: 10 questionsto help you make sense of a Qualitative research. https://casp-uk.net/casp-tools-checklists/

De Rosis, S., Cerasuolo, D., \& Nuti, S. (2020). Using patient-reported measures to drive change in healthcare: The experience of the digital, continuous and systematic PREMs observatory in Italy. BMC Health Services Research, 20(1), 315. https://doi.org/10.1186/s12913-020-05099-4

Gray, C. S., Tang, T., Armas, A., Backo-Shannon, M., Harvey, S., Kuluski, K., Loganathan, M., Nie, J. X., Petrie, J., Ramsay, T., Reid, R., Thavorn, K., Upshur, R., Wodchis, W. P., \& Nelson, M. (2020). Building a Digital Bridge to Support PatientCentered Care Transitions From Hospital to Home for Older Adults With Complex Care Needs: Protocol for a CoDesign, Implementation, and Evaluation Study. JMIR Research Protocols, 9(11), e20220.

https://doi.org/10.2196/20220

Greenhalgh, T., Wherton, J., Papoutsi, C., Lynch, J., Hughes, G., A'Court, C., Hinder, S., Fahy, N., Procter, R., \& Shaw, S. (2017). Beyond Adoption: A New Framework for Theorizing and Evaluating Nonadoption, Abandonment, and Challenges to the Scale-Up, Spread, and Sustainability of Health and Care Technologies. Journal of Medical Internet Research, 19(11), e367. https://doi.org/10.2196/jmir.8775

Hernar, I., Graue, M., Richards, D., Strandberg, R. B., Nilsen, R. M., Tell, G. S., \& Haugstvedt, A. (2019). Electronic capturing of patient-reported outcome measures on a touchscreen computer in clinical diabetes practice (the DiaPROM trial): A feasibility study. Pilot and Feasibility Studies, 5(1), 29. https://doi.org/10.1186/s40814-019-04194

Hong, T. H., Kim, M. K., Ryu, D. J., Park, J. S., Bae, G. C., \& Jeon, Y. S. (2021). The Reliability of Remote Patient-Reported Outcome Measures via Mobile Apps to Replace Outpatient Visits After Rotator Cuff Repair Surgery: Repetitive TestRetest Comparison Study for 1-Year Follow-up. Journal of Medical Internet Research, 23(3), e20989. https://doi.org/10.2196/20989

Horsley, T., Dingwall, O., \& Sampson, M. (2011). Checking reference lists to find additional studies for systematic reviews. The Cochrane Database of Systematic Reviews, 2011(8), MR000026. https://doi.org/10.1002/14651858.MR000026.pub2

Kingsley, C., \& Patel, S. (2017). Patient-reported outcome measures and patient-reported experience measures. BJA Education, 17(4), 137-144. https://doi.org/10.1093/bjaed/mkw060

Kyte, D., Ives, J., Draper, H., \& Calvert, M. (2016). Current practices in patient-reported outcome (PRO) data collection in clinical trials: A cross-sectional survey of UK trial staff and management. BMJ Open, 6(10), e012281. https://doi.org/10.1136/bmjopen-2016-012281

Lewin, S., Booth, A., Glenton, C., Munthe-Kaas, H., Rashidian, A., Wainwright, M., Bohren, M. A., Tunçalp, Ö., Colvin, C. J., Garside, R., Carlsen, B., Langlois, E. V., \& Noyes, J. (2018). Applying GRADE-CERQual to qualitative evidence synthesis findings: Introduction to the series. Implementation Science, 13(1), 2. https://doi.org/10.1186/s13012-017-0688-3 
Lindhardt, T., \& Nielsen, M. H. (2017). Older patients' use of technology for a post-discharge nutritional intervention A mixed-methods feasibility study. International Journal of Medical Informatics, 97, 312-321.

https://doi.org/10.1016/j.ijmedinf.2016.10.017

Malhotra, K., Buraimoh, O., Thornton, J., Cullen, N., Singh, D., \& Goldberg, A. J. (2016). Electronic capture of patientreported and clinician-reported outcome measures in an elective orthopaedic setting: A retrospective cohort analysis. BMJ Open, 6(6), e011975. https://doi.org/10.1136/bmjopen-2016-011975

Mannheim, I., Schwartz, E., Xi, W., Buttigieg, S. C., McDonnell-Naughton, M., Wouters, E. J. M., \& van Zaalen, Y. (2019). Inclusion of Older Adults in the Research and Design of Digital Technology. International Journal of Environmental Research and Public Health, 16(19), 3718. https://doi.org/10.3390/ijerph16193718

Marengoni, A., Angleman, S., Melis, R., Mangialasche, F., Karp, A., Garmen, A., Meinow, B., \& Fratiglioni, L. (2011). Aging with multimorbidity: A systematic review of the literature. Ageing Research Reviews, 10(4), 430-439.

https://doi.org/10.1016/j.arr.2011.03.003

May, C. (2013). Towards a general theory of implementation. 14.

May, C. R., Johnson, M., \& Finch, T. (2016). Implementation, context and complexity. Implementation Science, 11(1), 141. https://doi.org/10.1186/s13012-016-0506-3

McCleary N. J., Wigler D., Berry D., Sato K., Abrams T., Chan J., Enzinger P., Ng K., Wolpin B., Schrag D., Fuchs C. S., Hurria A., \& Meyerhardt J. A. (2013). Feasibility of Computer-Based Self-Administered Cancer-Specific Geriatric Assessment in Older Patients With Gastrointestinal Malignancy. The Oncologist, 18(1), 64-72. https://doi.org/10.1634/theoncologist.2012-0241

McDonagh, L. K., Saunders, J. M., Cassell, J., Curtis, T., Bastaki, H., Hartney, T., \& Rait, G. (2018). Application of the COM$B$ model to barriers and facilitators to chlamydia testing in general practice for young people and primary care practitioners: A systematic review. Implementation Science, 13(1), 1-19. https://doi.org/10.1186/s13012-018-0821$\mathrm{y}$

Meirte, J., Hellemans, N., Anthonissen, M., Denteneer, L., Maertens, K., Moortgat, P., \& Daele, U. V. (2020). Benefits and Disadvantages of Electronic Patient-reported Outcome Measures: Systematic Review. JMIR Perioperative Medicine, 3(1), e15588. https://doi.org/10.2196/15588

Michie, S., Atkins, L., \& West, R. (2014). The Behaviour Change Wheel Book-A Guide To Designing Interventions. http://www.behaviourchangewheel.com/

Michie, S., van Stralen, M. M., \& West, R. (2011). The behaviour change wheel: A new method for characterising and designing behaviour change interventions. Implementation Science, 6(1), 42. https://doi.org/10.1186/1748-5908-642

Moher, D., Liberati, A., Tetzlaff, J., Altman, D. G., \& Group, T. P. (2009). Preferred Reporting Items for Systematic Reviews and Meta-Analyses: The PRISMA Statement. PLOS Medicine, 6(7), e1000097. https://doi.org/10.1371/journal.pmed.1000097

Moore, J. E., Mascarenhas, A., Bain, J., \& Straus, S. E. (2017). Developing a comprehensive definition of sustainability. Implementation Science, 12(1), 110. https://doi.org/10.1186/s13012-017-0637-1

Morton, K., Dennison, L., Band, R., Stuart, B., Wilde, L., Cheetham-Blake, T., Heber, E., Slodkowska-Barabasz, J., Little, P., McManus, R. J., May, C. R., Yardley, L., \& Bradbury, K. (2021). Implementing a digital intervention for managing uncontrolled hypertension in Primary Care: A mixed methods process evaluation. Implementation Science, $16(1), 57$. https://doi.org/10.1186/s13012-021-01123-1

Noyes, J., Booth, A., Cargo, M., Flemming, K., Harden, A., Harris, J., Garside, R., hannes, K., pantoja, tomas, \& thomas, james. (2021, September). Chapter 21: Qualitative evidence.

https://training.cochrane.org/handbook/current/chapter-21

O'Cathain, A., Croot, L., Duncan, E., Rousseau, N., Sworn, K., Turner, K. M., Yardley, L., \& Hoddinott, P. (2019). Guidance on how to develop complex interventions to improve health and healthcare. BMJ Open, 9(8), e029954.

https://doi.org/10.1136/bmjopen-2019-029954

Oliveira, A., Ferreira, P. L., Antunes, B., \& Pimentel, F. L. (2011). OnQol: Electronic device to capture QoL data in oncology: Difference between patients 65years or older and patients younger than 65years of age. Journal of Geriatric Oncology, 2(4), 253-258. https://doi.org/10.1016/j.jgo.2011.08.001 
Parker, S. J., Jessel, S., Richardson, J. E., \& Reid, M. C. (2013). Older adults are mobile too!Identifying the barriers and facilitators to older adults' use of mHealth for pain management. BMC Geriatrics, 13(1), 1-8. https://doi.org/10.1186/1471-2318-13-43

Paslakis, G., Fischer-Jacobs, J., Pape, L., Schiffer, M., Gertges, R., Tegtbur, U., Zimmermann, T., Nöhre, M., \& Zwaan, M. de. (2019). Assessment of Use and Preferences Regarding Internet-Based Health Care Delivery: Cross-Sectional Questionnaire Study. Journal of Medical Internet Research, 21(5), e12416. https://doi.org/10.2196/12416

Plsek, P., \& Greenhalgh, T. (2001). Complexity Science: The Challenge Of Complexity In Health Care. BMJ: British Medical Journal, 323(7313), 625-628. JSTOR. https://www.jstor.org/stable/25467871

Remillard, M. L., Mazor, K. M., Cutrona, S. L., Gurwitz, J. H., \& Tjia, J. (2014). Systematic review of the use of online questionnaires of older adults. Journal of the American Geriatrics Society, 62(4), 696-705.

https://doi.org/10.1111/jgs.12747

Ross, J., Stevenson, F., Dack, C., Pal, K., May, C., Michie, S., Barnard, M., \& Murray, E. (2018). Developing an implementation strategy for a digital health intervention: An example in routine healthcare. BMC Health Services Research, 18(1), 794. https://doi.org/10.1186/s12913-018-3615-7

Rousseau, N., Turner, K. M., Duncan, E., O'Cathain, A., Croot, L., Yardley, L., \& Hoddinott, P. (2019). Attending to design when developing complex health interventions: A qualitative interview study with intervention developers and associated stakeholders. PLOS ONE, 14(10), e0223615. https://doi.org/10.1371/journal.pone.0223615

Tassiopoulos, K., Roberts-Toler, C., Fichtenbaum, C. J., \& Koletar, S. L. (2020). Web-Based Data Collection for Older Adults Living With HIV in a Clinical Research Setting: Pilot Observational Study. Journal of Medical Internet Research, 22(11), e18588. https://doi.org/10.2196/18588

Thomas, J., \& Harden, A. (2008). Methods for the thematic synthesis of qualitative research in systematic reviews. BMC Medical Research Methodology, 8(1), 45. https://doi.org/10.1186/1471-2288-8-45

Timlin, D., McCormack, J. M., \& Simpson, E. E. (2021). Using the COM-B model to identify barriers and facilitators towards adoption of a diet associated with cognitive function (MIND diet). Public Health Nutrition, 24(7), 1657-1670. https://doi.org/10.1017/S1368980020001445

Tong, A., Flemming, K., McInnes, E., Oliver, S., \& Craig, J. (2012). Enhancing transparency in reporting the synthesis of qualitative research: ENTREQ. BMC Medical Research Methodology, 12(1), 181. https://doi.org/10.1186/1471-2288$12-181$

United Nations. (2020). World population ageing, 2019 highlights.

Weldring, T., \& Smith, S. M. S. (2013). Patient-Reported Outcomes (PROs) and Patient-Reported Outcome Measures (PROMs). Health Services Insights, 6, 61-68. https://doi.org/10.4137/HSI.S11093

Wilson, J., Heinsch, M., Betts, D., Booth, D., \& Kay-Lambkin, F. (2021). Barriers and facilitators to the use of e-health by older adults: A scoping review. BMC Public Health, 21(1), 1556. https://doi.org/10.1186/s12889-021-11623-w

Wohlin, C., Mendes, E., Felizardo, K. R., \& Kalinowski, M. (2020). Guidelines for the search strategy to update systematic literature reviews in software engineering. Information and Software Technology, 127, 106366. https://doi.org/10.1016/j.infsof.2020.106366

Wolpert, M. (2014). Uses and Abuses of Patient Reported Outcome Measures (PROMs): Potential Iatrogenic Impact of PROMs Implementation and How It Can Be Mitigated. Administration and Policy in Mental Health, 41(2), 141-145. https://doi.org/10.1007/s10488-013-0509-1 